\title{
Dynamic Characteristics of Deep Dolomite Under One-Dimensional Static and Dynamic Loads
}

\author{
Jianguo Wang ${ }^{1,2} \cdot$ Yang $\mathrm{Liu}^{3} \cdot$ Kegang $\mathrm{Li}^{1}$
}

Received: 24 July 2019/Accepted: 17 December 2019/Published online: 31 December 2019

(C) The Author(s) 2019

\begin{abstract}
The failure characteristics of rock subjected to impact disturbance under one-dimensional static axial compression are helpful for studying the problems of pillar instability and rock burst in deep, high geostress surrounding rock under blasting disturbances. Improved split Hopkinson pressure bar equipment was used for one-dimensional dynamic-static combined impact tests of deepseated dolomite specimens under axial compression levels of $0,12,24$, and $36 \mathrm{MPa}$. The experimental results demonstrate that the dolomite specimens exhibit strong brittleness. The dynamic strength always maintains a strong positive correlation with the strain rate when the axial compression is fixed; when the strain rate is close, the dynamic elasticity modulus and peak strength of the specimens first increase and then decrease with the increase in axial compression, and the peak value appears at $24 \mathrm{MPa}$. The impact resistance of specimens can be enhanced when the axial compression is 12 or $24 \mathrm{MPa}$, but when it increases to $36 \mathrm{MPa}$, the damage inside the specimen begins to cause damage to the dynamic rock strength.
\end{abstract}

Kegang Li

13808734055@163.com

Jianguo Wang

wangjg0831@163.com

Yang Liu

554872270@qq.com

1 Faculty of Land Resources Engineering, Kunming University of Science and Technology, Kunming 650093, Yunnan, China

2 College of Civil and Architectural Engineering, Yunnan Agricultural University, Kunming 650201, Yunnan, China

3 School of Civil Engineering, Anhui Jianzhu University, Hefei 230601, Anhui, China
Prior to the rock macroscopic failure, the axial static load changes the rock structure state, and it can store strain energy or cause irreversible damage.

Keywords One-dimensional axial compression . Dynamic and static combined loading - Rock burst . Dynamic characteristics - Fragmentation degree

\section{Introduction}

Hard rock mining cannot be separated from blasting. While ensuring effective crushing of the exploded rock mass, it will inevitably cause disturbances to the structures of deep pillars and floors, among others. In particular, the instantaneous release of energy by tens of tons of explosives in large-scale ore blasting will inevitably cause a vibration in the surrounding rock mass and even directly induce rock explosion in the near-space rock mass under high ground stress. Figure 1 illustrates the measured waveform of the blasting vibration of a falling mine in the lion rock mine. The peak vibration velocity exceeds $6 \mathrm{~cm} / \mathrm{s}$. Figure 2 presents the failure diagram of the roadway side following mine blasting, with large disturbances [1].

The theories and methods for dynamic stability analysis of rock mass were summarized by Dong et al. [2]. Rock blasting was divided into strain and impact types by Feng et al. [3] and Chen et al. [4]. The strain type is rock damage caused by energy released from the unloading of energy storage in rock mass during deep engineering excavation, while the impact type is generated under the dynamic load disturbance of blasting following the formation of deep engineering. Records of rock burst phenomena in the mine indicate that most rock burst phenomena occur after largescale ore blasting, and the occurrence frequency tends to 


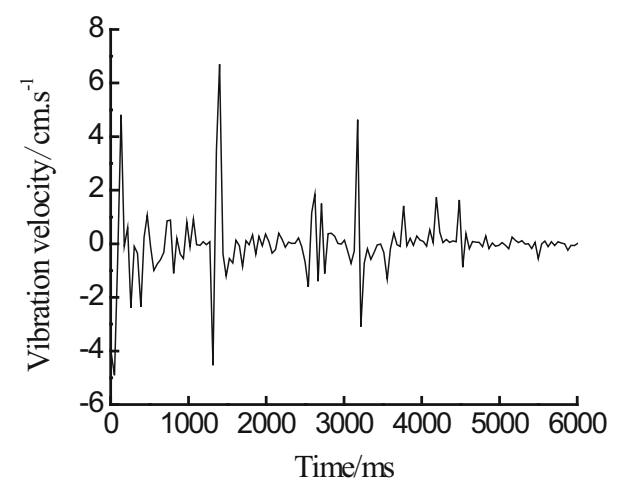

Fig. 1 Measured vibration waveform of deep tribal mine

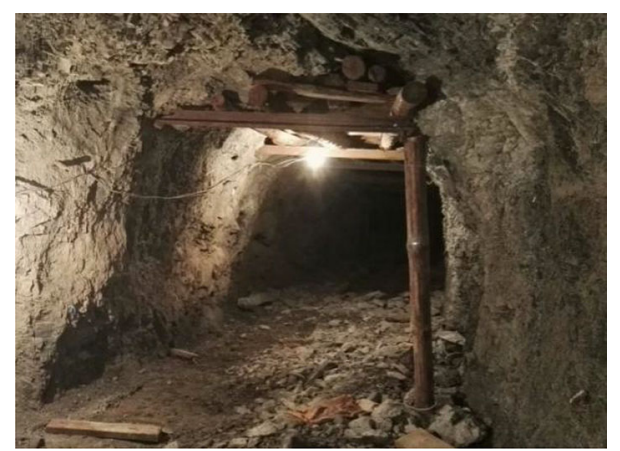

Fig. 2 Failure diagram of roadway side wall blasting

increase with depth [5]. Based on this understanding, the dynamic mechanical properties of rocks under static loading and the rock burst mechanism are thoroughly revealed based on the characteristics of the rock itself, the actual load model of the deep rock, and the interaction mechanism of the energy storage and disturbance energy of the rock itself, providing important practical significance for safe mining in deep mines [6].

The mechanical properties of deep rock masses under the action of static and impact stresses have been widely studied [7-15] with the aid of split Hopkinson pressure bar (SHPB) test equipment and achieved fruitful research results. The axial static pressure in the rock uniaxial compressive strength is approximately $60 \%$ and provides the strongest shock resistance. When the axial pressure is constant, the energy absorption speed is slow if the impact energy is small, and the energy absorption speed is accelerated if the impact energy is large. The sandstone strength has a positive correlation with the strain rate and exhibits an exponential function relationship [16]. Within a certain axial pressure ratio range, the overall absorption and release energy of the specimen exhibits three processes of "absorption-release-absorption" as the impact load increases [12, 13]. The authors have also conducted extensive research on rock impact dynamics with SHPB equipment, such as "Impact response tests of layered medium with SHPB" [17], "Low temperature effect of saturated granite on dynamic characteristics under high strain rates" [18], and "Experimental study on dynamic mechanical properties of red sandstone under low temperatures" [19]. However, previous studies mostly used sandstone or granite with effective homogeneity, while studies on deep field sampling combined with measured geostatic pressure loading and axial static pressure need to be supplemented. For example, in the room-pillar mining method, the supporting pillar formed in the stope can be regarded as a structure with only axial pressure but no confining pressure, and the disturbance law of blasting mining on the lower stope is related to the stability of the existing stope. Using SHPB testing equipment, combined with the deep copper mine ground pressure of lion rock, we selected 12,24 , and $36 \mathrm{MPa}$ as three horizontal axial static pressures on dolomite samples to conduct one-dimensional dynamic-static combined impact tests and a conventional uniaxial impact test, and explored the effects of axial compression on the rock dynamic mechanical properties in terms of the stress-strain curve, strength of character, strain rate effect, and destruction form.

\section{One-Dimensional Dynamic-Static Combined Impact Tests}

\section{Sample Preparation}

The rock samples were obtained from a large block of stoped ore in the No. 16 middle section of the Lion Copper Mine of the Yuxi Mining Industry, located in Yunnan Province, China, which is over $400 \mathrm{~m}$ from the vertical ground and over $800 \mathrm{~m}$ from the top of the mountain. The international institute of rock mechanics has confirmed that the SHPB test of rock material provides a relatively accurate length-diameter ratio between 0.5 and 1.0. The length-diameter ratio of the test piece used was 1.0, and the dimension of the cylindrical test piece was $50 \times 50 \mathrm{~mm}$. The sample rock was ore-bearing (copper) blue-gray dolomite, the end-face non-parallelism and axial non-perpendicularity of processing qualified specimens are both less than $0.02 \mathrm{~mm}$, as shown in Fig. 3, and the basic physical parameters and static load performance are displayed in Table 1.

\section{Experimental System}

A shock test was performed on the improved SHPB equipment, as illustrated in Fig. 4. The bars and punches of the SHPB device were all made of $40 \mathrm{Cr}$ alloy steel, with a density of $7800 \mathrm{~kg} / \mathrm{m}^{3}$, longitudinal wave velocity of $5400 \mathrm{~m} / \mathrm{s}$, bar diameter of $50 \mathrm{~mm}$, and incident and 

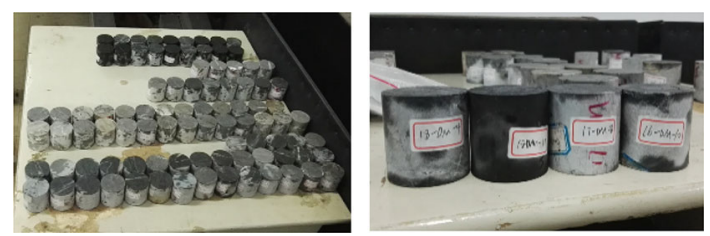

Fig. 3 Processing qualified dolomite specimen

transmission bar length of $2 \mathrm{~m}$. A spindle-shaped punch driven by high-pressure nitrogen was used to achieve half sinusoidal wave loading in the range of a $10^{1}-10^{3} \mathrm{~s}^{-1}$ strain rate [20].

\section{Experimental Principle}

Based on the one-dimensional elastic wave theory, the incident, transmission, and reflection pulses measured by the strain gauge were processed by the three-wave method [21], and the time stress and strain of the specimen could be determined, following which the stress and strain relationship as well as the average strain rate was obtained. The formulae are as follows:

$\varepsilon_{\mathrm{s}}=\frac{u_{1}}{u_{2}}=\frac{C_{0}}{l_{\mathrm{s}}} \int_{0}^{t_{0}}\left(\varepsilon_{i}-\varepsilon_{r}-\varepsilon_{t}\right) \mathrm{d} t$

$\dot{\varepsilon}_{\mathrm{s}}=\frac{\mathrm{d} \varepsilon_{\mathrm{s}}}{\mathrm{d} t}=\frac{C_{0}}{l_{\mathrm{s}}}\left(\varepsilon_{i}-\varepsilon_{r}-\varepsilon_{t}\right)$

$\sigma_{\mathrm{s}}=\frac{P_{1}+P_{2}}{2 A_{\mathrm{s}}}=\frac{E A_{0}}{2 A_{\mathrm{s}}}\left(\varepsilon_{i}+\varepsilon_{r}+\varepsilon_{t}\right)$,

where $\sigma_{\mathrm{s}}$ is the stress; $\varepsilon_{\mathrm{s}}$ is the strain; $\dot{\varepsilon}$ is the strain rate; $u_{1}$ and $u_{2}$ are the end displacements of the input and output bars in contact with the specimen, respectively; $C_{0}$ is the elastic longitudinal wave velocity in the pressure bar system; $P_{1}$ and $P_{2}$ are the forces acting on both ends of the specimen by the input and output bars, respectively; $E$ is the elastic modulus of the pressure bar system; $l_{\mathrm{s}}$ is the specimen length; $A_{\mathrm{s}}$ is the cross-sectional area of the specimen; and $A_{0}$ is the cross-sectional area of the pressure bar.

\section{Experimental Scheme}

The data from the geopressure study of the Lion Copper Mine indicate that the maximum geostress direction of the deep rock mass in this mine is horizontal or close to horizontal [1]. In general, the maximum horizontal principal stress in the middle section No. 15 of stoped ore is 37.7 MPa, the minimum horizontal principal stress is 14.48 $\mathrm{MPa}$, and the vertical principal stress is higher than $10 \mathrm{MPa}$. The dynamic mechanical properties of dolomite under the combined action of axial static and impact loads in one dimension were studied to describe the mechanical properties of rock subjected to disturbances under the complex stress environment of the deep mine accurately. The axial static pressure should be based on $0 \%, 25 \%$, $50 \%$, and $75 \%$ of the static compressive strength, with values of $0,12,24$, and $36 \mathrm{MPa}$ selected for the test. Four samples were obtained for each group, and the pre-applied axial pressure had to be maintained unchanged prior to each impact. Vaseline was applied on both ends of the specimen to ensure that the specimen section fits well with the bar prior to the test. The initial loading air pressure was set at $0.4 \mathrm{MPa}$ and then increased by $0.1 \mathrm{MPa}$ each time, and the impact process was recorded by high-speed photography. The experimental loading model under the combined action of one-dimensional static load and impact is illustrated in Fig. 5. $P_{C}$ is the loading total load, $P_{\text {as }}$ is the preloading static load, and $P_{\mathrm{d}}$ is the impact dynamic load.

Table 1 Static mechanical parameters of dolomite

\begin{tabular}{llllll}
\hline Lithology $\begin{array}{l}\text { Loading rate }(\mathrm{MPa} / \\
\mathrm{s})\end{array}$ & $\begin{array}{l}\text { Density }(\mathrm{kg} / \\
\left.\mathrm{m}^{3}\right)\end{array}$ & $\begin{array}{l}\text { Wave velocity }(\mathrm{m} / \\
\mathrm{s})\end{array}$ & $\begin{array}{l}\text { Compressive strength } \\
(\mathrm{MPa})\end{array}$ & $\begin{array}{l}\text { Deformation modulus } \\
(\mathrm{GPa})\end{array}$ \\
\hline Dolomite & 0.5 & 2828 & 3918 & 47.24 & 20.41 \\
\hline
\end{tabular}

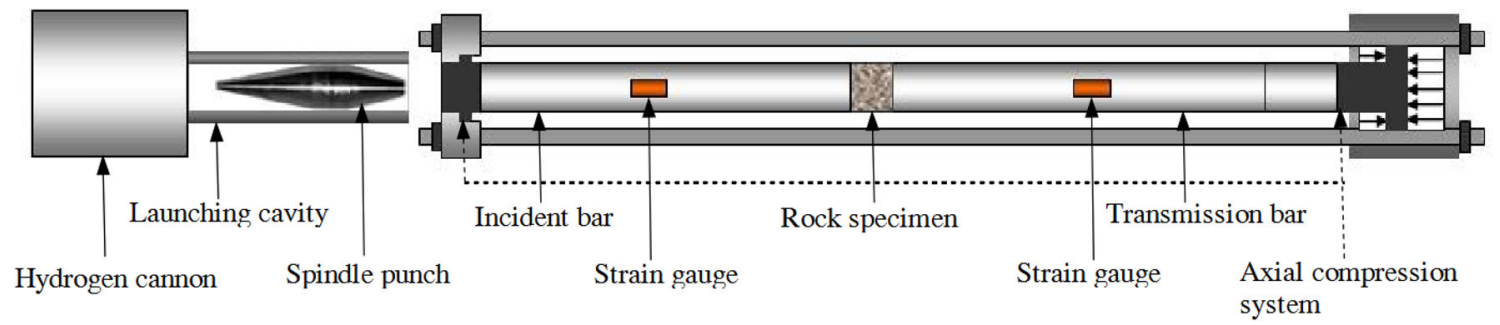

Fig. 4 Schematic of one-dimensional static and dynamic combined SHPB device 


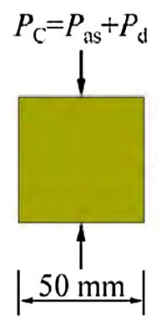

(a) Loading of specimen;

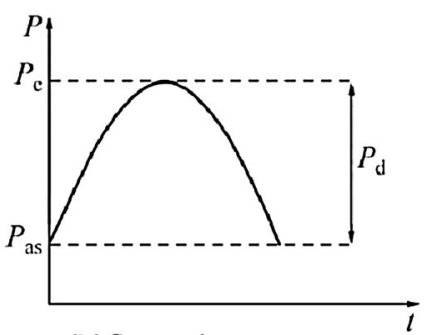

(b) Stress-time curve

Fig. 5 Model sketch of one-dimensional coupled static and dynamic loads

\section{Analysis and Discussion of Experimental Results \\ Effect of Strain Rate on Stress-Strain Characteristics}

Figure 6 illustrates the dynamic impact $\sigma-\varepsilon$ curve of the dolomite specimens under the conditions of $0,12,24$, and $36 \mathrm{MPa}$ static axial pressure. Under several conditions of the loading strain rate $\dot{\varepsilon}$, the strain values $\varepsilon$ were all less than 0.01 , indicating that the rock sample was brittle. It can be observed that, with the gradual increase in $P_{\text {as }}$, the trend of the peak stress (shown below with $\sigma_{\mathrm{m}}$ ) increasing with

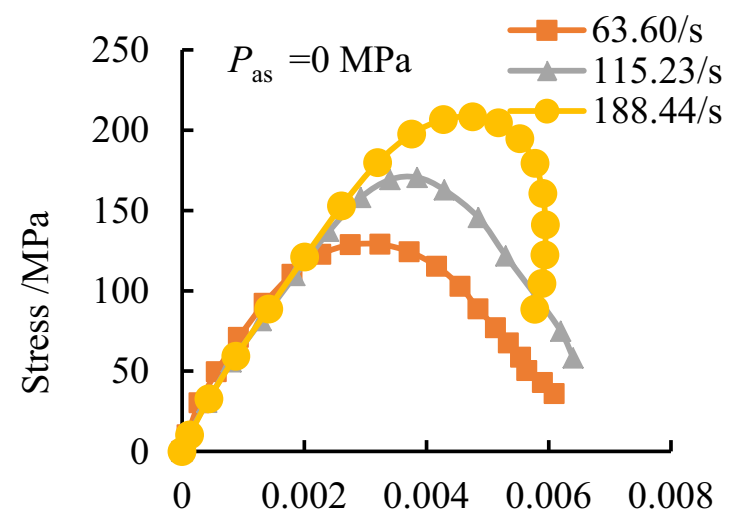

Strain

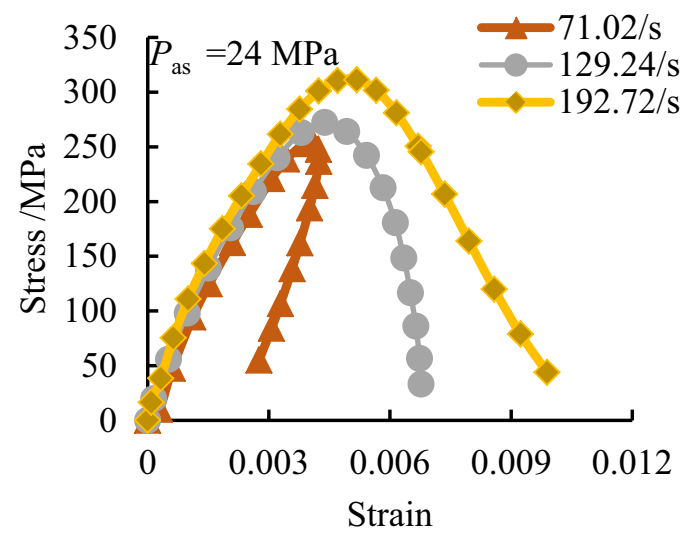

the increase in $\dot{\varepsilon}$ did not change, but the amplitude of $\sigma_{\mathrm{m}}$ increased significantly as $\dot{\varepsilon}$ decreased. Thereafter, the peak $\varepsilon$ increased gradually with the increase in $\dot{\varepsilon}$. When $P_{\text {as }}$ was $0 \mathrm{MPa}$, the $\sigma-\varepsilon$ curve was type II; when $P_{\text {as }}$ was $12 \mathrm{MPa}$ and $24 \mathrm{MPa}$, the type gradually changed from II to I with the increase in $\dot{\varepsilon}$. When $P_{\text {as }}$ increased to $36 \mathrm{MPa}$, the curve forms changed to type II again. Overall, with the increase in $P_{\text {as }}$, the type of $\sigma-\varepsilon$ curve changed from I to II. It can be observed that the impact $\sigma-\varepsilon$ curve of the dolomite specimens under one-dimensional dynamic-static combined loading was significantly affected by $P_{\text {as }}$.

\section{Influence of Axial Pressure on Dynamic Mechanical Properties}

Path of $\sigma-\varepsilon$ Curves

When considering the $\sigma-\varepsilon$ curve with different $P_{\text {as }}$ values under the conditions of strain rate as 93 and $110 \mathrm{~s}^{-1}$, as illustrated in Figs. 7 and 8 , it is obvious that $P_{\text {as }}$ has a significant influence on the changing path of the dynamic $\sigma-\varepsilon$ curve of the specimens. When $P_{\text {as }}$ increased to 12 and $24 \mathrm{MPa}, \varepsilon$ exhibited a rebound and was a type II curve
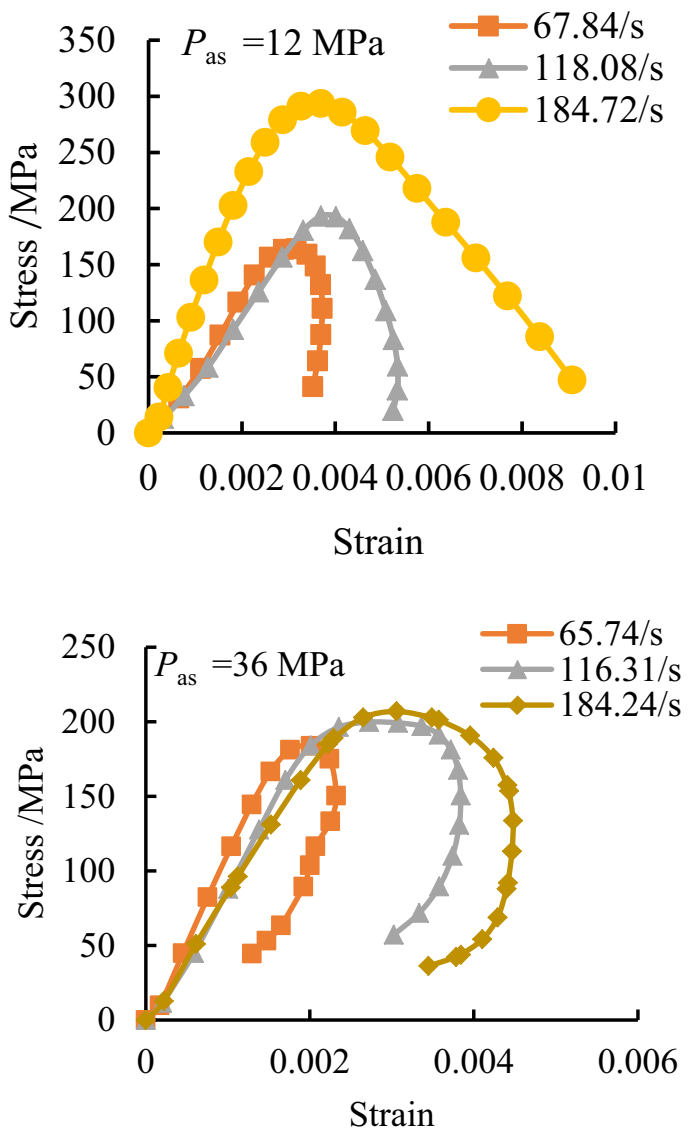

Fig. 6 Strain rate effects of $\sigma-\varepsilon$ curves under different axial compression conditions 


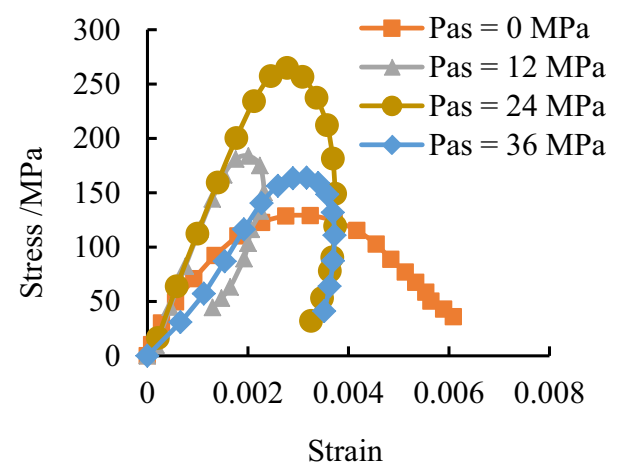

Fig. $7 \sigma-\varepsilon$ curves under the condition of $\dot{\varepsilon}=93 \mathrm{~s}^{-1}$

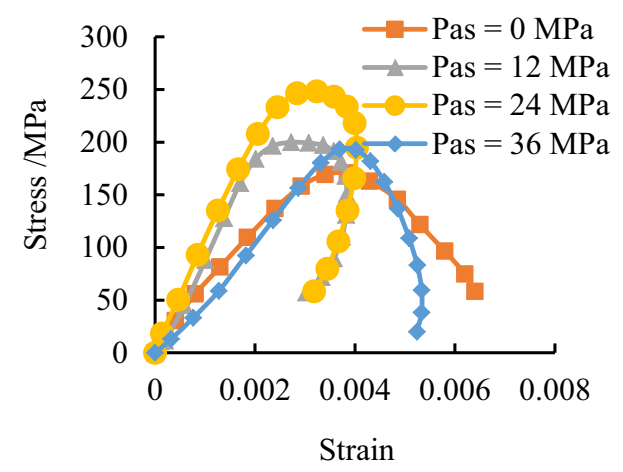

Fig. $8 \sigma-\varepsilon$ curves under the condition of $\dot{\varepsilon}=110 \mathrm{~s}^{-1}$

after the peak; when $P_{\text {as }}$ increased to $36 \mathrm{MPa}$, it tended to become a type I curve again. Moreover, $\sigma_{\mathrm{m}}$ achieved the maximum value under both types of $\dot{\varepsilon}$ when $P_{\text {as }}$ was $24 \mathrm{MPa}$.

Changes in Dynamic Elasticity Modulus and Peak Strength

Figures 9 and 10 illustrate the relation diagrams of the dynamic elastic modulus (represented by $E_{\mathrm{d}}$ ), $\sigma_{\mathrm{m}}$, and $P_{\text {as }}$ when $\dot{\varepsilon}$ was 93 and $110 \mathrm{~s}^{-1}$, respectively. In the selected axial pressure range of the test, $E_{\mathrm{d}}$ and $\sigma_{\mathrm{m}}$ both first

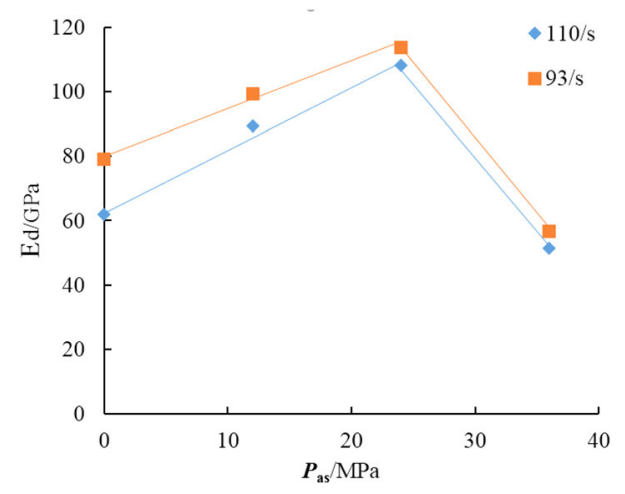

Fig. 9 Relationship of $E_{\mathrm{d}}$ versus $P_{\text {as }}$

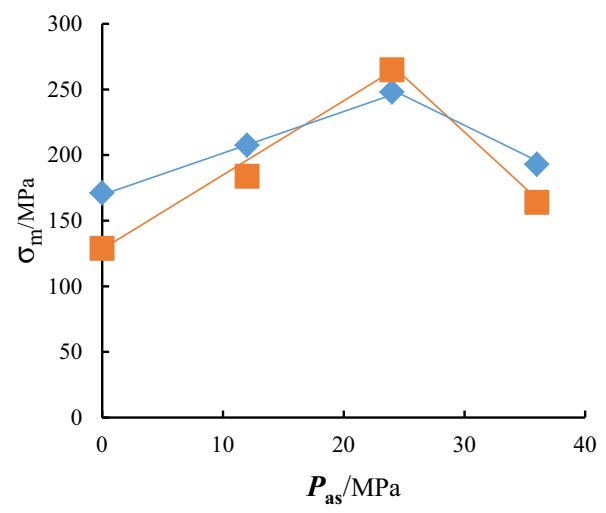

Fig. 10 Relationship of $\sigma_{\mathrm{m}}$ versus $P_{\text {as }}$

increased and then decreased with the increase in $P_{\text {as }}$ under the two conditions of $\dot{\varepsilon}$, and the apex of the trend line appeared at $P_{\mathrm{as}}=24 \mathrm{MPa}$. Taking the impact test data when $\dot{\varepsilon}$ was $110 \mathrm{~s}^{-1}$ as an example, when $P_{\text {as }}=0 \mathrm{MPa}$, $E_{\mathrm{d}}=61.96 \mathrm{GPa}$ and $\sigma_{\mathrm{m}}=171.14 \mathrm{GPa}$; when $P_{\text {as }}$ $=12 \mathrm{MPa}$ and $P_{\mathrm{as}}=24 \mathrm{MPa}$, the amplification of $E_{\mathrm{d}}$ was $44.0 \%$ and $74.5 \%$, respectively, while that of $\sigma_{\mathrm{m}}$ was $21.2 \%$ and $44.9 \%$, respectively. When $P_{\mathrm{as}}=36 \mathrm{MPa}, \sigma_{\mathrm{m}}$ increased by only $12.8 \%$, but $E_{\mathrm{d}}$ decreased by $17.1 \%$.

The change in the values of $E_{\mathrm{d}}$ and $\sigma_{\mathrm{m}}$ of dolomite specimens with $P_{\text {as }}$ was because a certain $P_{\text {as }}$ value can close the micro-cracks in the rock, making it difficult for rock deformation to occur. The $E_{\mathrm{d}}$ increased, and the impact resistance was strengthened. When $P_{\text {as }}$ continued to increase beyond a certain level, the fracture in the rock expanded under this static action, forming a penetrating surface, and internal damage began to occur, leading to a reduction in the value of $\sigma_{\mathrm{m}}$ of rock, and could no longer withstand excessive disturbance. When $P_{\text {as }}$ was increased to $36 \mathrm{MPa}, \sigma_{\mathrm{m}}$ began to decrease, but the impact resistance was still higher compared to that when $P_{\text {as }}$ was zero in this test.

\section{Analysis of Failure Characteristics}

The apparent cracks and failure modes during impact were observed by high-speed photography. The high-speed photography experiment adopted $384 \times 240$ resolution, and the image frame frequency was set to $10,000 \mathrm{fps}$, with one photograph captured each $0.1 \mathrm{~ms}$. The high-speed photography process was selected as $\dot{\varepsilon}=95.4 \mathrm{~s}^{-1}$ for analysis. Figure 11 illustrates the conventional failure modes of the impact specimens. It can be observed that, under uniaxial impact, the specimen forms a fracture surface in the axial direction and is basically parallel to the impact direction. No mutual extrusion exists between the fracture surfaces; thus, it belongs to the tensile failure 

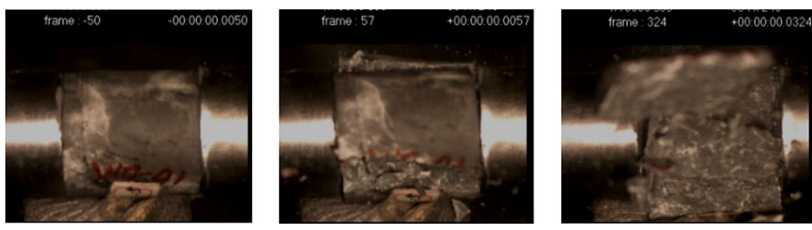

Fig. 11 High-speed photography of specimen failure process in the case of $P_{\text {as }}=0 \mathrm{MPa}$ and $\dot{\varepsilon}=95.4 \mathrm{~s}^{-1}$
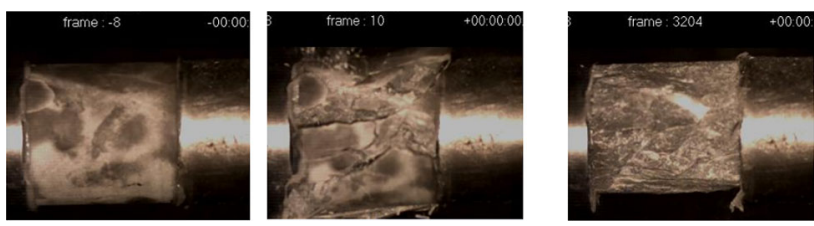

Fig. 12 High-speed photography of specimen failure process in the case of $P_{\text {as }}=12 \mathrm{MPa}$ and $\dot{\varepsilon}=98.61 \mathrm{~s}^{-1}$

mode and is caused by the Poisson effect of specimens under axial impact.

Figure 12 presents a high-speed photographic map of the failure process when $P_{\text {as }}=12 \mathrm{MPa}$ and $\dot{\varepsilon}=98.61 \mathrm{~s}^{-1}$. Owing to the effect of $P_{\text {as }}$, stress concentration occurred at the end of the specimen, compression zones were formed at both ends, and a potential shear fracture surface existed inside. When the disturbance reached the critical state of rock failure, the specimen began to be damaged, and the rock mass outside the shear surface collapsed outwards until the end of the disturbance and formed a double-cone shear surface. The falling debris appears to be thick in the middle and thin on both sides. Spalling failure occurred over the entire circumferential side of the specimen, but the overall bearing capacity was still in place, and it was still able to bear the loading axial pressure, without complete instability. This is consistent with the phenomenon whereby certain ore pillars can still bear pressure after rock burst under disturbances in production practice.

Figure 13 illustrates the impact failure process of specimens recorded by high-speed photography at an axial compression of $24 \mathrm{MPa}$ under similar strain rates. It can be observed that only the circumferential part of the specimen experienced spalling failure, and the integrity was superior to the final state of $P_{\mathrm{as}}=12 \mathrm{MPa}$. As can be observed from the analysis of the dynamic characteristics of the specimens
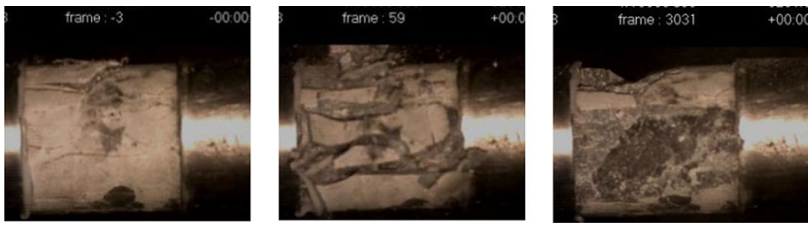

Fig. 13 High-speed photography of specimen failure process in the case of $P_{\mathrm{as}}=24 \mathrm{MPa}$ and $\dot{\varepsilon}=99.66 \mathrm{~s}^{-1}$
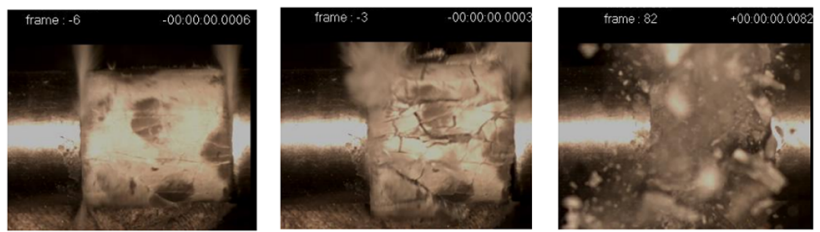

Fig. 14 High-speed photography of specimen failure process in the case of $P_{\text {as }}=36 \mathrm{MPa}$ and $\dot{\varepsilon}=99.24 \mathrm{~s}^{-1}$

in Sect. 3.2, when $P_{\text {as }}=36 \mathrm{MPa}$, internal cracks in dolomite specimens were formed, resulting in partial damage. Under the same impact load, the specimens exhibited overall failure and instability as well as fragmentation and could no longer bear axial pressure, as illustrated in Fig. 14.

\section{Analysis of Fragmentation Degree}

Figure 15 illustrates the fragments due to impact corresponding to four $P_{\text {as }}$ state types near $\dot{\varepsilon}=110 \mathrm{~s}^{-1}$. The fragments above $2 \mathrm{~cm}$ in length were divided into "large blocks," and the mass ratio between the mass and complete specimen was recorded as a "large proportion." A polyline diagram of the change in the large proportion with $P_{\text {as }}$ under the conditions of strain rates of $\dot{\varepsilon}=110 \mathrm{~s}^{-1}$ and $\dot{\varepsilon}=93 \mathrm{~s}^{-1}$ was drawn, as presented in Fig. 16. It can be observed that, when $\dot{\varepsilon}=110 \mathrm{~s}^{-1}$, the large proportion first increased with the increase in $P_{\text {as }}$, and when $P_{\text {as }}=24 \mathrm{MPa}$, the large proportion was the largest. Only a few small pieces fell off the impact specimen surface, indicating that the static action greatly improved the rock anti-disturbance ability. When $P_{\mathrm{as}}=36 \mathrm{MPa}$, the rock disturbance resistance began to weaken, and the large proportion was 0.27 , but still higher than 0.23 when no axial pressure was applied. The change in the trend of the large proportion of $\dot{\varepsilon}=93 \mathrm{~s}^{-1}$ was consistent with that of $\dot{\varepsilon}=110 \mathrm{~s}^{-1}$. When $P_{\text {as }}=36 \mathrm{MPa}$, the large proportion was 0.51 , which was higher than that of the non-axial state of 0.41 .

\section{Conclusion and Discussion}

1. Both the peak stress and dynamic elastic modulus of the dolomite specimens achieved the maximum values when the axial pressure was $24 \mathrm{MPa}$ under the test conditions, and the peak stress decreased when the axial pressure increased, resulting in additional broken specimens, indicating that the axial pressure within a certain range could improve the rock impact resistance.

2. Axial static pressure made the specimen store strain energy. Under the axial compression of $36 \mathrm{MPa}$, the rock's anti-disturbance ability began to weaken. 


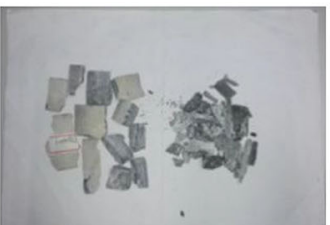

(a) $0 \mathrm{MPa}$

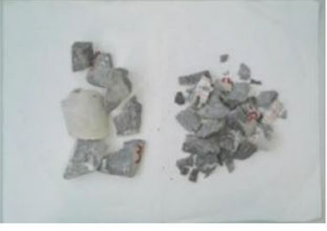

(b) $12 \mathrm{MPa}$

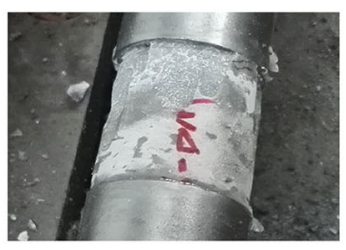

(c) $24 \mathrm{MPa}$

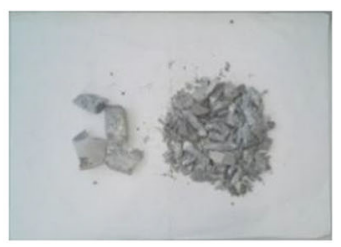

(d) $36 \mathrm{MPa}$

Fig. 15 Specimen failure process in the case of different axial compressions and $\dot{\varepsilon}=109.6 \mathrm{~s}^{-1}$

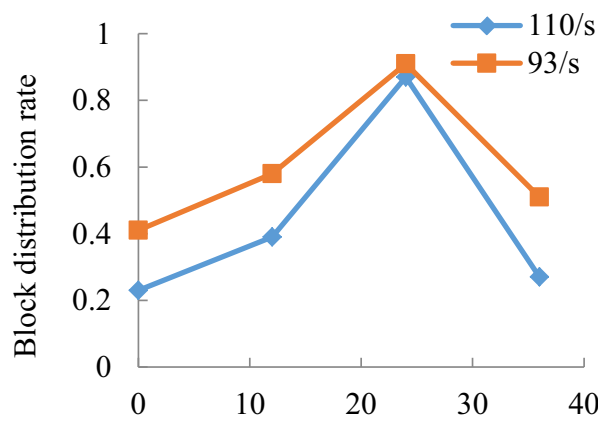

Axial compression/MPa

Fig. 16 Relationship between block distribution and axial compression

However, under the two test conditions of strain rate of $93 \mathrm{~s}^{-1}$ and $110 \mathrm{~s}^{-1}$, the proportion of the crushed mass was still higher than that without axial compression.

3. When the incident energy was similar in the intact state, the overall absorption and release energy of the specimen presented a process of the absorption first and then release energy with the increase in axial pressure. With the increase in impact load, the rate of energy absorption and release was accelerated.

Acknowledgements This work was financially supported by the National Natural Science Foundation of China (Grant Nos. 41672303 and 51604006) and the Postdoctoral Science Foundation of the Kunming University of Science and Technology (No. 10988856); the authors also thank the Program for Innovative Research Team (in Science and Technology) in University of Yunnan Province for their support.

\section{Compliance with Ethical Standards}

Conflict of interest On behalf of all authors, the corresponding author states that there is no conflict of interest.

Open Access This article is licensed under a Creative Commons Attribution 4.0 International License, which permits use, sharing, adaptation, distribution and reproduction in any medium or format, as long as you give appropriate credit to the original author(s) and the source, provide a link to the Creative Commons licence, and indicate if changes were made. The images or other third party material in this article are included in the article's Creative Commons licence, unless indicated otherwise in a credit line to the material. If material is not included in the article's Creative Commons licence and your intended use is not permitted by statutory regulation or exceeds the permitted use, you will need to obtain permission directly from the copyright holder. To view a copy of this licence, visit http://creativecommons.org/licenses/by/4.0/.

\section{References}

1. W. Zhao, Dynamic mechanical properties of hard rock under high geostress. Dissertation, Kunming University of Science and Technology, 2017

2. L. Dong, J. Wang, X. Li et al., Dynamic stability analysis of rockmass: a review. Adv. Civ. Eng. 2018(4), 1-22 (2018)

3. X. Feng, B. Chen, H. Ming et al., Evolution law and mechanism of rockbursts in deep tunnels: immediate rockburst. Chin. J. Rock Mech. Eng. 31(3), 433-444 (2012). (in Chinese)

4. B. Chen, X. Feng, H. Ming et al., Evolution law and mechanism of rockburst in deep tunnel: time delayed rockburst. Chin. J. Rock Mech. Eng. 31(3), 561-569 (2012). (in Chinese)

5. W.D. Ortlepp, Observation of mining-induced faults in an intact rock mass at depth. Int. J. Rock Mech. Min. Sci. 37(1-2), 423-436 (2000)

6. J.B. Zhu, Z.Y. Liao, C.A. Tang, Numerical SHPB tests of rocks under combined static and dynamic loading conditions with application to dynamic behavior of rocks under in situ stresses. Rock Mech. Rock Eng. 49(10), 3935-3946 (2016)

7. X. Li, Z. Zhou, T.-S. Lok et al., Innovative testing technique of rock subjected to coupled static and dynamic loads. Int. J. Rock Mech. Min. Sci. 45(5), 739-748 (2008)

8. P. Bailly, F. Delvare, J. Vial et al., Dynamic behavior of an aggregate material at simultaneous high pressure and strain rate: SHPB triaxial tests. Int. J. Impact Eng. 38(2-3), 73-84 (2011)

9. Z. Yin, X. Li, J. Jin et al., Failure characteristics of high stress rock induced by impact disturbance under confining pressure unloading. Trans. Nonferr. Met. Soc. China 22(1), 175-184 (2012)

10. M. Omidvar, M. Iskander, S. Bless, Stress-strain behavior of sand at high strain rates. Int. J. Impact Eng. 49, 192-213 (2012)

11. T. Yin, P. Wang, X. Li et al., Effects of thermal treatment on physical and mechanical characteristics of coal rock. J. Cent. South Univ. 23(9), 2336-2345 (2016)

12. J. Wang, S. Liang, Q. Gao et al., Experimental study of jointed angles impact on energy transfer characteristics of simulated rock material. J. Cent. South Univ. (Sci. Technol.) 49(5), 1237-1243 (2018). (in Chinese)

13. W. Wang, H. Wang, D. Li et al., Strength and failure characteristics of natural and water-saturated coal specimens under static and dynamic loads. Shock Vib. 2018(3), 1-15 (2018)

14. F. Gong, X. Li, J. Zhao et al., Experimental research progress of dynamic characteristics for rock materials on triaxial SHPB apparatus. Sci. Technol. Rev. 27(18), 106-111 (2009) 
15. F.Q. Gong, X.F. Si, X.B. Li et al., Dynamic triaxial compression tests on sandstone at high strain rates and low confining pressures with split Hopkinson pressure bar. Int. J. Rock Mech. Min. Sci. 113, 211-219 (2019)

16. X. Si, F. Gong, X. Li et al., Dynamic Mohr-Coulomb and HoekBrown strength criteria of sandstone at high strain rates. Int. J. Rock Mech. Min. Sci. 115, 48-59 (2019)

17. J. Wang, Q. Gao, H. Lu et al., Impact response tests of layered medium with SHPB. J. Vib. Shock 34(19), 192-197, 212 (2015). (in Chinese)

18. J. Wang, Y. Yang, Y. Guo et al., Low temperature effect of saturated granite on dynamic characteristics under high strain rates. Rock Soil Mech. 38(Supp. 2), 163-169 (2017). (in Chinese)
19. Y. Yang, R. Yang, J. Wang et al., Experimental study on dynamic mechanical properties of red sandstone under low temperatures. J. China Coal Soc. 43(04), 967-975 (2018). (in Chinese)

20. W. Chen, B. Song, Split Hopkinson (Kolsky) Bar (Springer, New York, 2011), pp. 5-15

21. T.T. Wang, B. Shang, Three-wave mutual-checking method for data processing of SHPB experiments of concrete. J. Mech. 30(5), 5-10 (2014)

Publisher's Note Springer Nature remains neutral with regard to jurisdictional claims in published maps and institutional affiliations. 